Araştırma Makalesi - Research Article

\title{
Allee Etkisi Altındaki Av-Avcı Sisteminin Zamana Bağlı Değişimi
}

\begin{abstract}
Yadigar Şekerci ${ }^{1 *}$
Geliş / Received: 20/11/2019

Revize / Revised: 18/04/2020

Kabul / Accepted: 20/04/2020

ÖZ

Allee etkisi altındaki avın büyüme katkısının baskılandığı ve avcı ölüm oranının zaman içinde doğrusal olarak değiştiği av-avcı modelinin zamana bağlı dinamikleri ele alınmıştır. Bu çalışmada, av-avcı sisteminin zamana bağlı dinamik yapısı ikili adi diferansiyel denklem ile incelenmiştir. Çok sayıdaki nümerik simülasyonlar sayesinde sistemin çeşitli zamansal yapıya sahip olduğu ve sistemin avcının ölüm katsayısındaki değişim ile dengelenebileceği gösterilmiştir. Elde edilen sonuçlar göstermektedir ki Allee etkisi altında ve avcı popülasyonunun artmasıyla birlikte av üzerindeki baskının artması ile system, avı neslinin tükenmesine zorlamıştır ve dolayısıyla avın olmaması avcının neslini de tüketmiştir.
\end{abstract}




\title{
Temporal Response of Predator-Prey System with the Allee Effect
}

\begin{abstract}
Temporal dynamics of a predator-prey model, in which predator mortality rate varies linearly in time, is considered with the assumption that prey growth is stressed by the strong Allee effect. In this work, temporal structure of prey-predator system consisting of two coupled ordinary differential equations is examined. By means of extensive numerical simulations it is shown that the system has rich temporal structure and the system can be stabilizes with the change in predator mortality rate. Obtained results show that with an increasing stress on prey due to Allee affect and the increase in predator population size, the system push the prey to extinct and then the system is extinct due to absence of prey for predator.
\end{abstract}




\section{INTRODUCTION}

The origin of the Allee term is based on an experimental study carried by Warder Clyde Allee. Alee has shown that when there are more individuals within the tank goldfish grow faster [1]. Further experiment and observations prompted him to believe that grouping will increase the individuals survivals rate and that cooperation can be essential to the overal survival of society $[1,2]$. When the 'Allee principle' was presented, the first focus of this issue was the competition role between species and within the species $[1,3]$.

The traditional population dynamics indicate that due to cooperation for same limited resources, the population undergo a diminished total growth rate at a higher density and and higher growth rate at lower density [4-9]. On the otherhand, Allee effect defences the reverse idea. According to this idea, members within a group require support from another member in order to survive, and this idea is assisted by a group defence against predators or by feeding together on prey. Hence this term can be defined as positive density dependence between any component of population density [3,10]. Odum [11] refers to it as Allee's Principle, the idea was turned into what we now commonly consider Allee effect.

In brief, the Allee effect means that the growth rate per capita rises rather than declines with population density over a certain distance. Strong Allee effect corresponds to the growth rate per capita is negative once the density is zero and weak Allee effect corresponds to the growth rate is close to zero [1]. The Allee effect of social mammals was first described by [12], and named after the ecologist Allee [1,13-15] it has been applied to a large variety of species. Much attention has been paid to the corresponding temporal models in $[16,17]$ and to the corresponding spatial models of predator-prey systems with spatial pattern formation have been observed in such systems [18-23]. Petrovskii et al. [24] have analyzed the effect of Allee as a potential lagging process. For a particular set of parameters, they reveal three types of regimes in which the invasive prey is influenced by the Allee effect. One of this regime is anomalous extinction which it is observed in this work in temporal case. To reveal the structure of this regime, a map is introduced to detail the different domain corresponding to different regime under the effect of Allee effect [24].

Spatial patterning of prey-predator model is examined in [24] and the temporal structure of the model is explained as a parameter plane. Hence in this work temporal structure of a predator-prey model is detailed with the addition of varying mortality rate of predator. Base on the obtained parameter plane map in [24], the Allee effect stress on the existence of species is discussed.

In this work, a model describing predator-prey interactions are studied. Temporal variations of predator mortality rate is discussed to detail the temporal response of the model which is already under the stress of strong Allee effect. Based on extensive numerical simulations, it is obtained that temporal structure of this model has rich dynamics.

\section{MAIN EQUATION \& EQUILIBRIUM ANALYSIS}

We consider one dimension predator-prey model studied earlier in spatial case [24-27]. The nonspatial counterpart of the system is as follows:

$$
\begin{aligned}
& \frac{d u}{d t}=\gamma u(u-\beta)(1-u)-\frac{u v}{1+\alpha u} \\
& \frac{d v}{d t}=\frac{u v}{1+\alpha u}-\delta v
\end{aligned}
$$

Here $u$ and $v$ are the densities of prey and predator, respectively, at time $t$ and $\delta$ is the predator mortality rate. Due to biological meanings all components of the system are positive. For more details on system parametrizations and its dimensional version and the procedure for being dimensionless see [24]. The systems` (1-2) steady state is a solution of the following equations: 


$$
\begin{aligned}
& \gamma u(u-\beta)(1-u)-\frac{u v}{1+\alpha u}=0, \\
& \frac{u v}{1+\alpha u}-\delta v=0 .
\end{aligned}
$$

One of the steady states is extinction $E_{1}=(0,0)$ is always stable for any values of possitive system parameters. Other is semi-trivial equilibrium $E_{2}=(\beta, 0), E_{3}=(1,0)$, extinction of predator case. The predator free steady state is saddle. See [24] for more details on the stability of these boundary states and the phase plane of the system. $E_{4}=(u, v)$ is the last steady state of the system. The steady state of the coexistence system is as follows:

$$
v=\gamma(u-\beta)(1-u)(1+\alpha u), \quad u=\frac{\delta}{1-\delta \alpha}
$$

Jacobian matrix of the system (1-2) is as follows:

$$
J=\left(\begin{array}{ll}
J_{11} & J_{12} \\
J_{21} & J_{22}
\end{array}\right)
$$

where

$$
\begin{aligned}
& J_{11}=2 u \gamma-3 u^{2} \gamma-\gamma \beta+2 u \gamma \beta-\frac{v}{(1+u \alpha)^{2}} ; \\
& J_{12}=-\frac{u}{(1+u \alpha)^{2}} ; \\
& J_{21}=\frac{v}{(1+u \alpha)^{2}} ; \\
& J_{22}=\frac{u}{(1+u \alpha)^{2}}-\delta .
\end{aligned}
$$

The eigenvalues are the solutions of the following characteristic equation

$$
\operatorname{det}\left(J_{i}-\lambda I\right)=0
$$

where $J_{i}$ is the jacobian matrix (6), $i=1,2,3,4$, and $I$ is the unit matrix. See [24] for further details on the stability analysis of the system.

It is presumed that at the beginning of the distribution, the domain already includes all communities at the density rate corresponding to the stationary state $(\tilde{u}, \tilde{v})$ with a slight perturbation in prey density. Therefore the initial condition takes the following constant form, i.e.,

$$
u(x, 0)=\tilde{u}+\varepsilon, \quad v(x, 0)=\tilde{v},
$$

where $\tilde{u}, \tilde{v}$ are the steady states of the system dynamics, given by Eq. (11) with $\varepsilon=0.1$. 


$$
\tilde{u}=\frac{\delta}{1-\alpha \delta}, \quad \tilde{v}=\gamma(1+\alpha \tilde{u})(\tilde{u}-\beta)(1-\tilde{u})
$$

Finite difference scheme is used for ordinary differential equations with the steps of the numerical mesh are chosen as $\Delta t=0.05$. It is checked that these values are small enough not to results in any numerical artifacts. Since the main purpose of this work is to detail the temporal structure of the system under the light of the work is carried by [24], Fig. 14 in [24] is used as a bifurcation diagram of the system. So the parameters are chosen accordingly as $\alpha=0.5, \beta=0.28$ and $\gamma=7$.

\section{NUMERICAL SIMULATIONS}

The prey-predator system is examined that prey growth is damped by a strong Allee effect with the attention on changing mortality rate of predator. The rate of zooplankton mortality, i.e., $\delta$, is defined differently in this study. The mortality rate is specified as a function of time and keep the other system parameters unchanged.

Here it is assumed the mortality rate to be a linearly decreasing function meaning that predator mortality decreases over time and this condition raises stress on prey. And then this mortality rate is taken as an increasing function to see the systems' temporal response. The reason for choosing the predator mortality rate as a different function is therefore to show a change in the dynamic structure of the system. The possible choice of $\delta$ is given as follows:

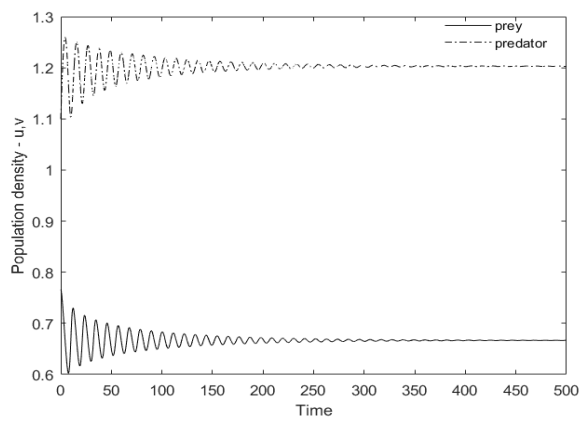

(a)
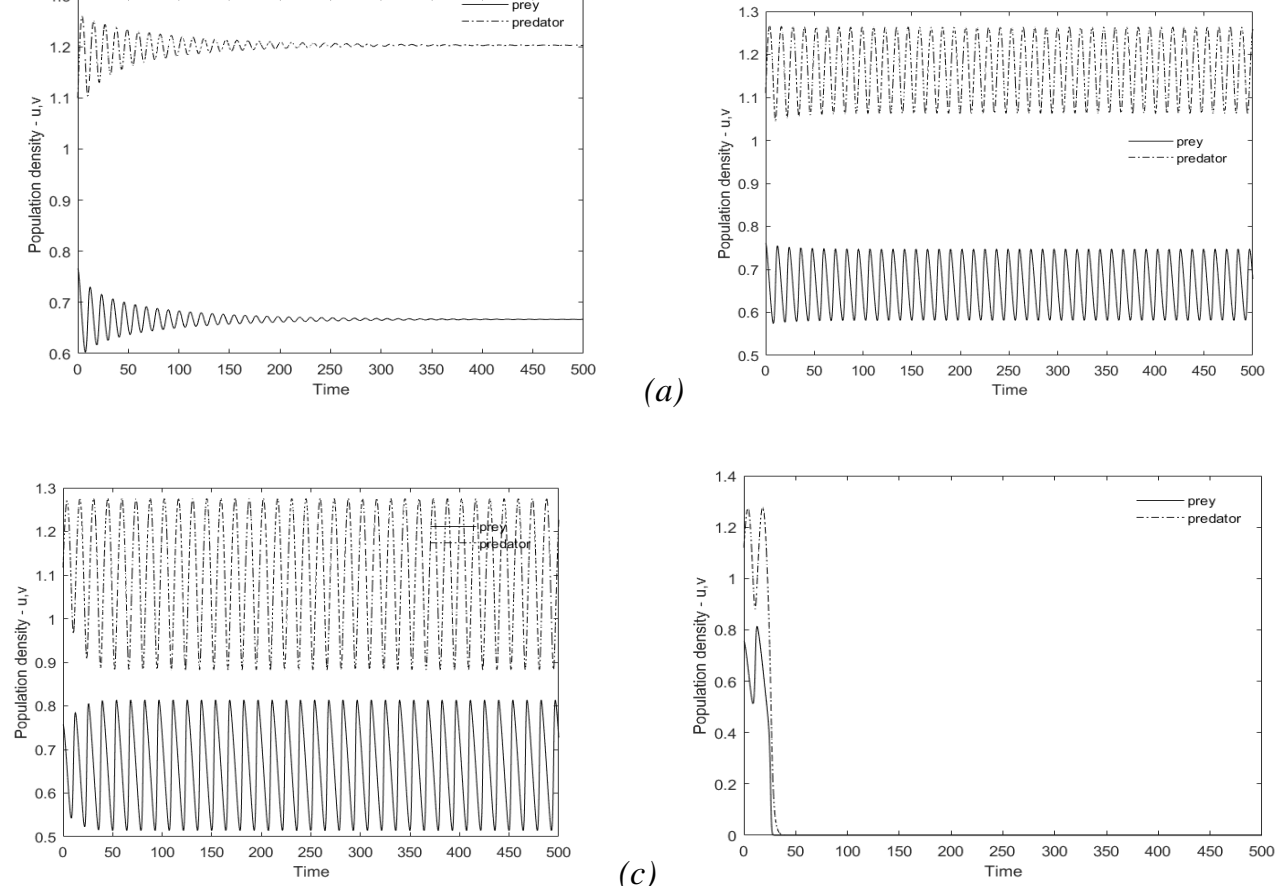

(d)

Figure 1. Snapshots of the prey (solid line) and predator (dashed-dotted line) versus time obtained for a) $\delta_{t}=0.5$,b) $\delta_{t}=0.497$, c) $\delta_{t}=0.495$ and d) $\delta_{t}=0.494$ for $t=500$ obtained for parameters $\omega=0$. The initial values of the system are obtained from Eqs.7-8 for given system parameters defined in Section II. 


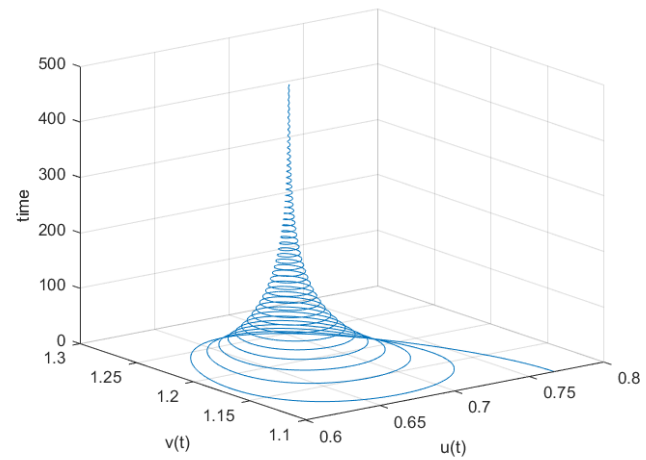

(a)

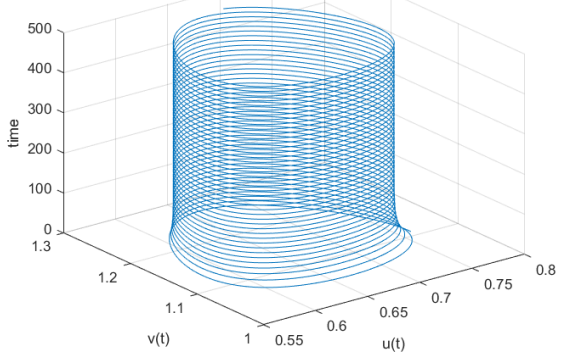

(b)

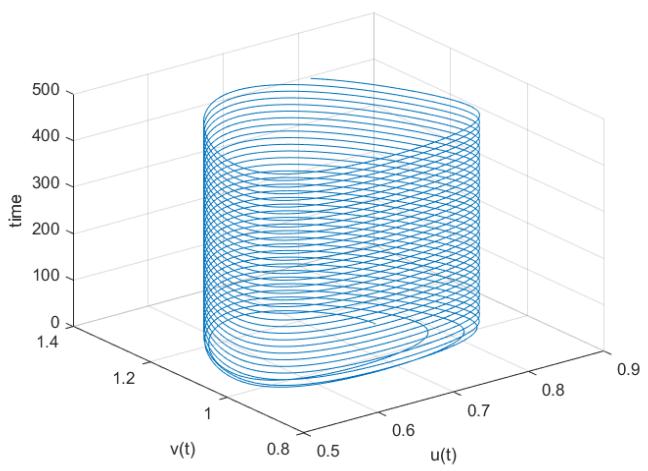

(c)

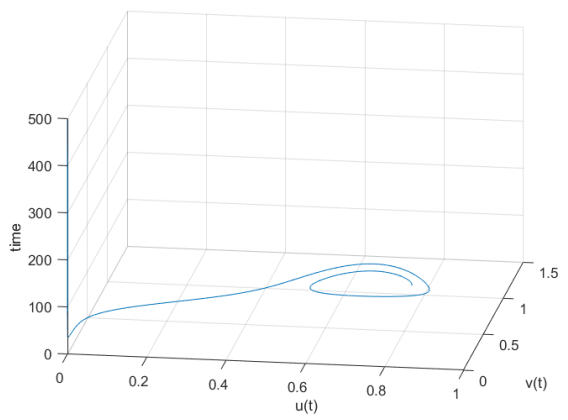

(d)

Figure 2. Phase plane structure for prey and predator for fixed values of delta in time a) $\delta_{t}=0.5$, b) $\delta_{t}=0.497$, c) $\delta_{t}=0.495$ and d) $\delta_{t}=0.494$ for $t=500$ obtained for parameters $\omega=0$. The initial values of the system are obtained from Eqs.7-8 for given system parameters defined in Section II.

$$
\delta=\delta_{t} \text { for } \omega=0, \quad \delta=\delta_{t} \pm \omega\left(t-t_{1}\right) \text { for } \omega>0
$$

Here, $t_{1}$ is initial time, i.e., $t_{1}=0, \delta_{t}$ is predator mortality rate before the temporal change starts, and

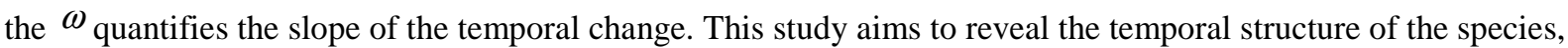
both the decreasing and the increasing values of mortality rate of predator is considered.

Therefore, we give some numerical simulations for three possible approaches. The first is without a temporal change, i.e., $(\omega=0)$ in Figs. 1-2. Second is with the case of the decrease in mortality rate for $(\omega>0)$ in Figs. 3-4. The last one is the case of the increase in mortality rate for the values of $(\omega>0)$ in Figs. 5-6. It should be emphasized here that, contrary to [24], $\delta$ is taken as a function of time to see the bifurcation behavior of the system.

Figure 1 shows snapshots of prey and predator temporal distributions obtained at different values of $\delta$ for $t=500$. For the values of $\delta_{t}=0.5$, the system has damping oscillations and with a decrease in $\delta$, i.e., $\delta_{t}=0.497$, the system develops periodic oscillations and the system has a Hopf bifurcation between these values. For a decrease in $\delta$, i.e., $\delta_{t}=0.495$, the size of oscillations are increased. For a slightly further decrease in $\delta$, i.e., $\delta_{t}=0.494$, the species are extinct and the system goes to extinct after few oscillations. Fig. 2 shows the corresponding phase plane structure of the prey-predator system over given time. 
Figure 3 exhibits snapshots of prey and predator temporal distributions obtained at different values of $\omega$ for $t=2000$ and for the values of $\delta_{t}=0.5$. Here $\delta=\delta_{t}-\omega\left(t-t_{1}\right)$. For $\omega=1 \times 10^{-6}$, the system has damping oscillations for the beginning of the time and then the system stabilizes for a while at its coexistence steady state and then the system develops oscillations with an increase in size. With a slight increase in $\omega$, i.e., $\omega=2 \times 10^{-6}$, the system develops oscillations for different sort of size. With an increase in $\omega$, i.e., $\omega=3 \times 10^{-6}$, the developing oscillations are extinct suddenly between the time values $t \approx 1900$. With a further increase in $\omega$, i.e., $\omega=4 \times 10^{-6}$, the time for extinction observed is observed earlier than previous value of $\omega$. And for the last value of $\omega$, i.e., $\omega=4 \times 10^{-4}$, the system only develops few oscillations and the species go extinct. Fig. 4 shows the corresponding phase plane structure of the prey-predator system over given time in three dimensions.

Fig. 5 displays snapshots of prey and predator temporal distributions obtained at different values of $\omega$ for $t=2000$ and for the values of $\delta_{t}=0.495$. Here $\delta=\delta_{t}+\omega\left(t-t_{1}\right)$ for $\omega=3 \times 10^{-6}$, the system has damping oscillations for the beginning of the system and then the system stabilizes for a while at its coexistence steady state. With a decrease in $\omega$, i.e., $\omega=1 \times 10^{-5}$, the system again has a damping oscillations but in this case the stabilisation of the system happens earlier. With an increase in $\omega$, i.e., $\omega=55 \times 10^{-6}$, the damping oscillations are not stabilise at the systems' steady state. The population of the prey increase and correspondingly the population density of predator decrease in time. Finally they merge each other between the time values $t=1800$ and $t=2000$. With a further increase in $\omega$, i.e., $\omega=2 \times 10^{-4}$, due to the decrease in predator population the prey population increase first and then the system reach its carrying capacity and the population level of prey is stabilise. Fig. 6 shows the corresponding phase plane structure of the prey-predator system over given time in three dimensions to show the phase plane evolution in time. 

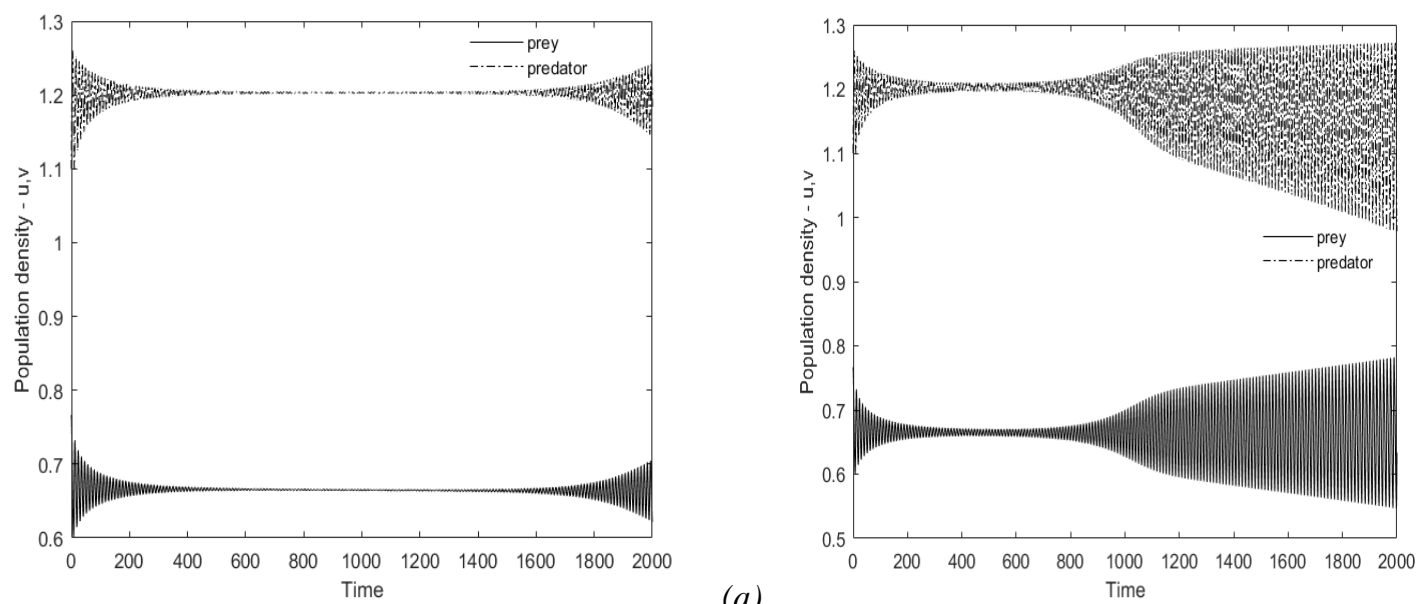

(a)
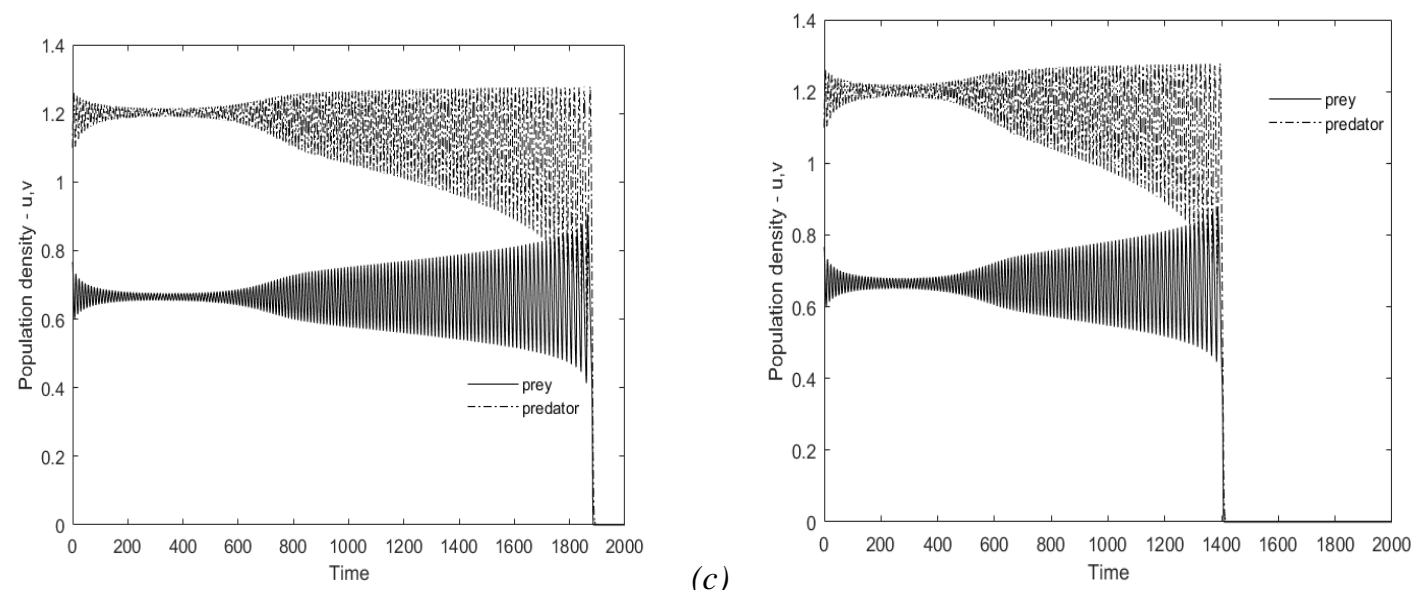

(d)
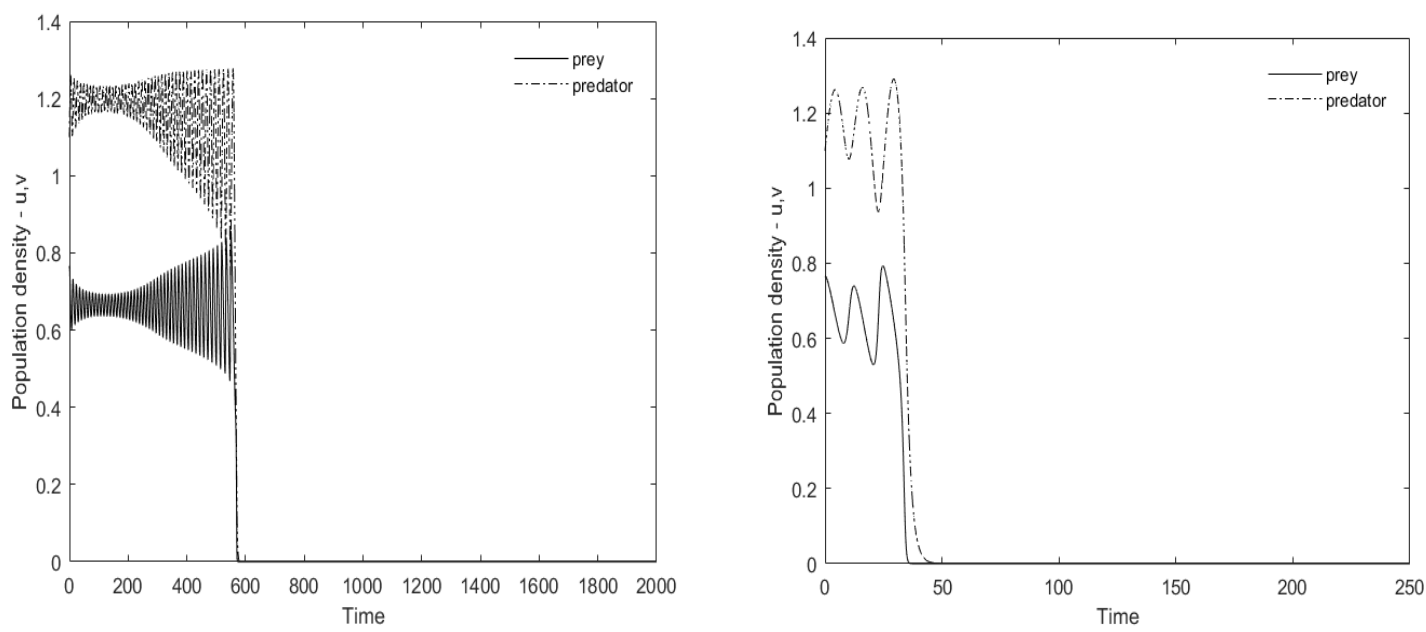

(e)

(f)

Figure 3. Snapshots of the prey (solid line) and predator (dashed-dotted line) versus time obtained for $\delta_{t}=0.5$ a) $\omega=1 \times 10^{-6}$, b) $\omega=2 \times 10^{-6}$, c) $\omega=3 \times 10^{-6}$, d) $\omega=4 \times 10^{-6}$, e) $\omega=1 \times 10^{-5}$ and f) $\omega=4 \times 10^{-4}$ for $t=2000$. The initial values of the system are obtained from Eqs.7-8 for given system parameters defined in Section II. 

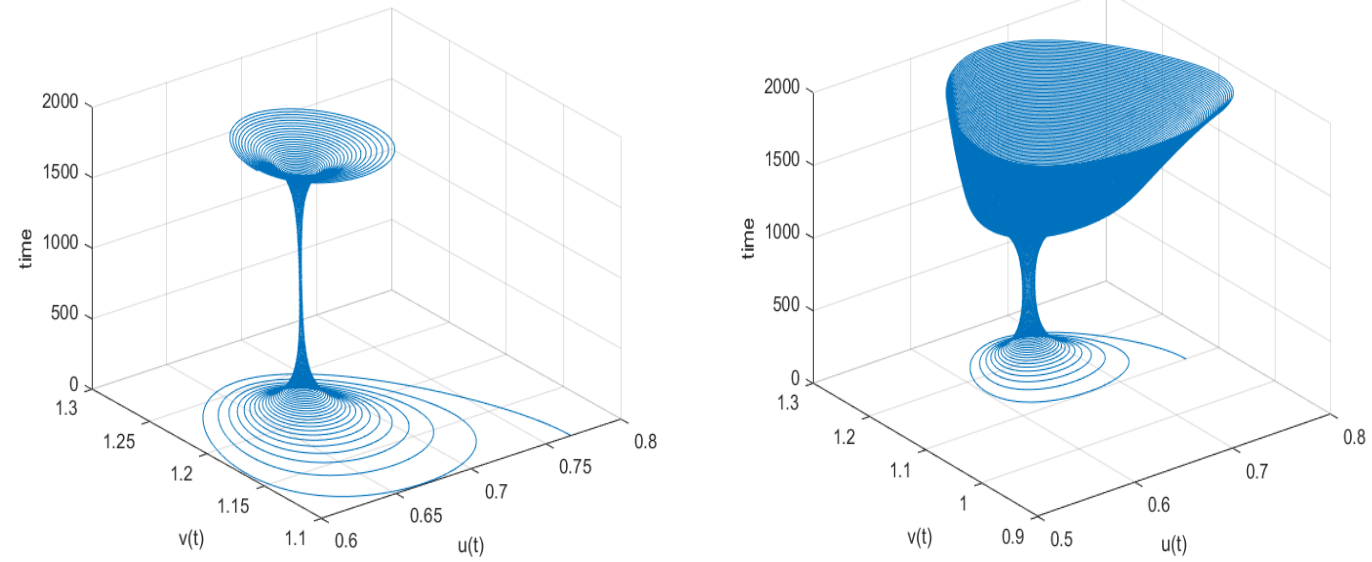

(a)

(b)
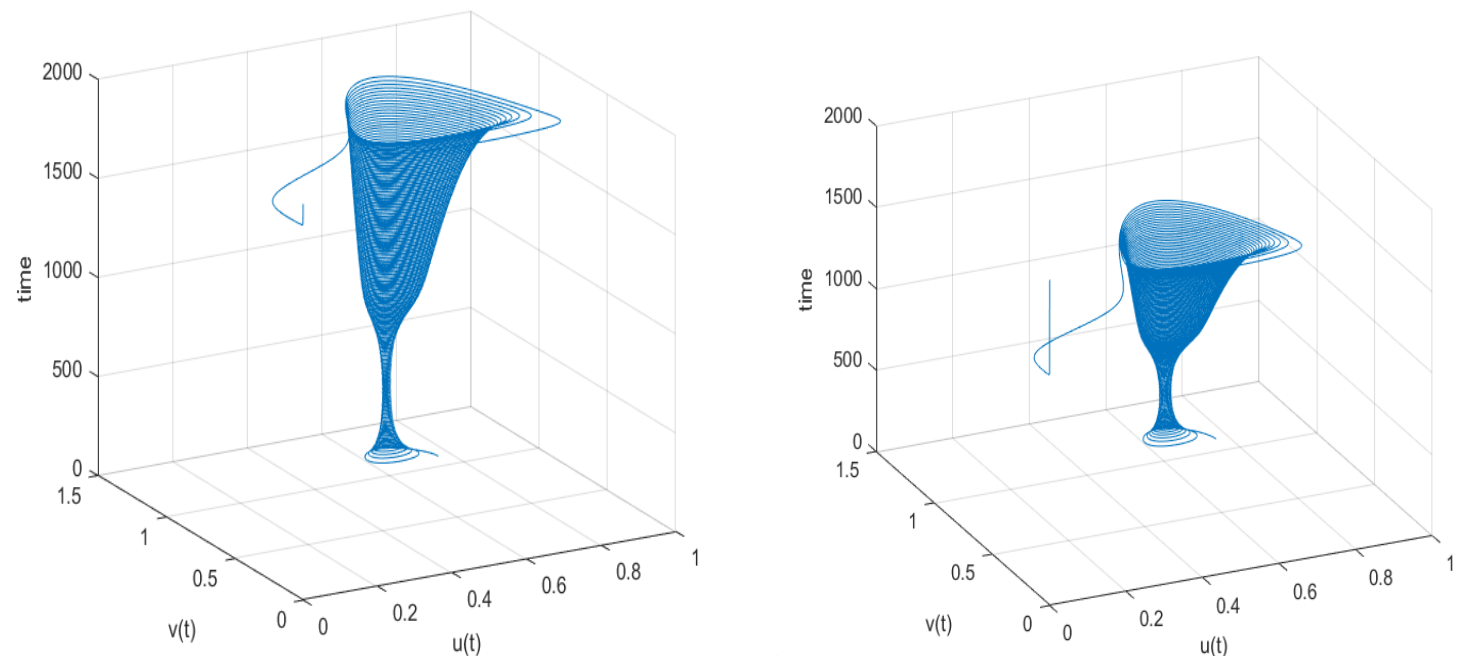

(c)
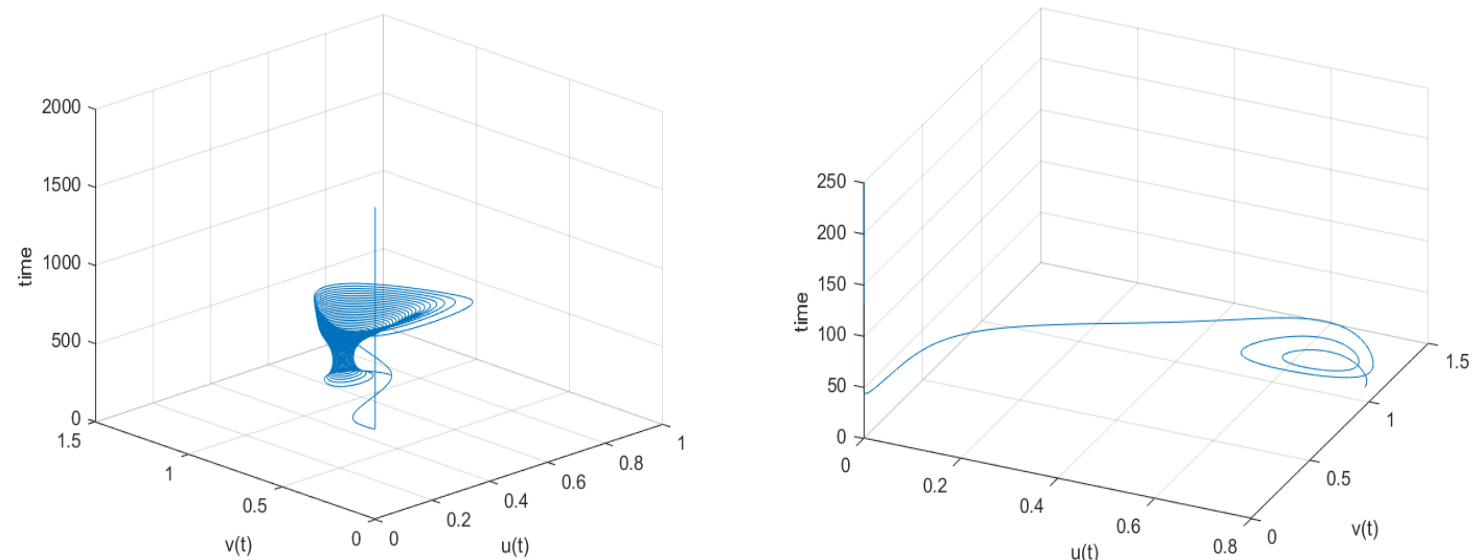

(e)

Figure 4. Phase plane structure for prey and predator for fixed values of delta in time $\delta_{t}=0.5$ a) $\omega=1 \times 10^{-6}$, b) $\omega=2 \times 10^{-6}$, c) $\omega=3 \times 10^{-6}$, d) $\omega=4 \times 10^{-6}$ e) $\omega=1 \times 10^{-5}$ and f) $\omega=4 \times 10^{-4}$ for $t=2000$. The initial values of the system are obtained from Eqs.7-8 for given system parameters defined in Section II. 


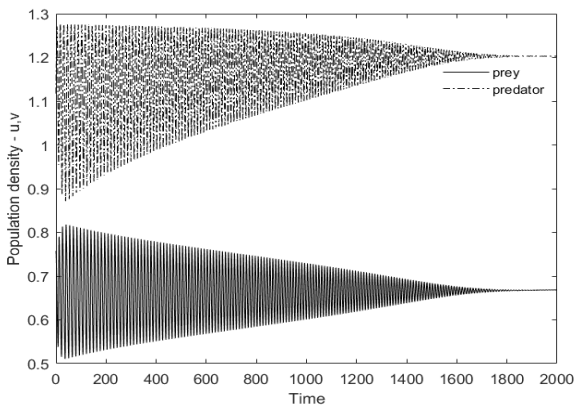

(a)
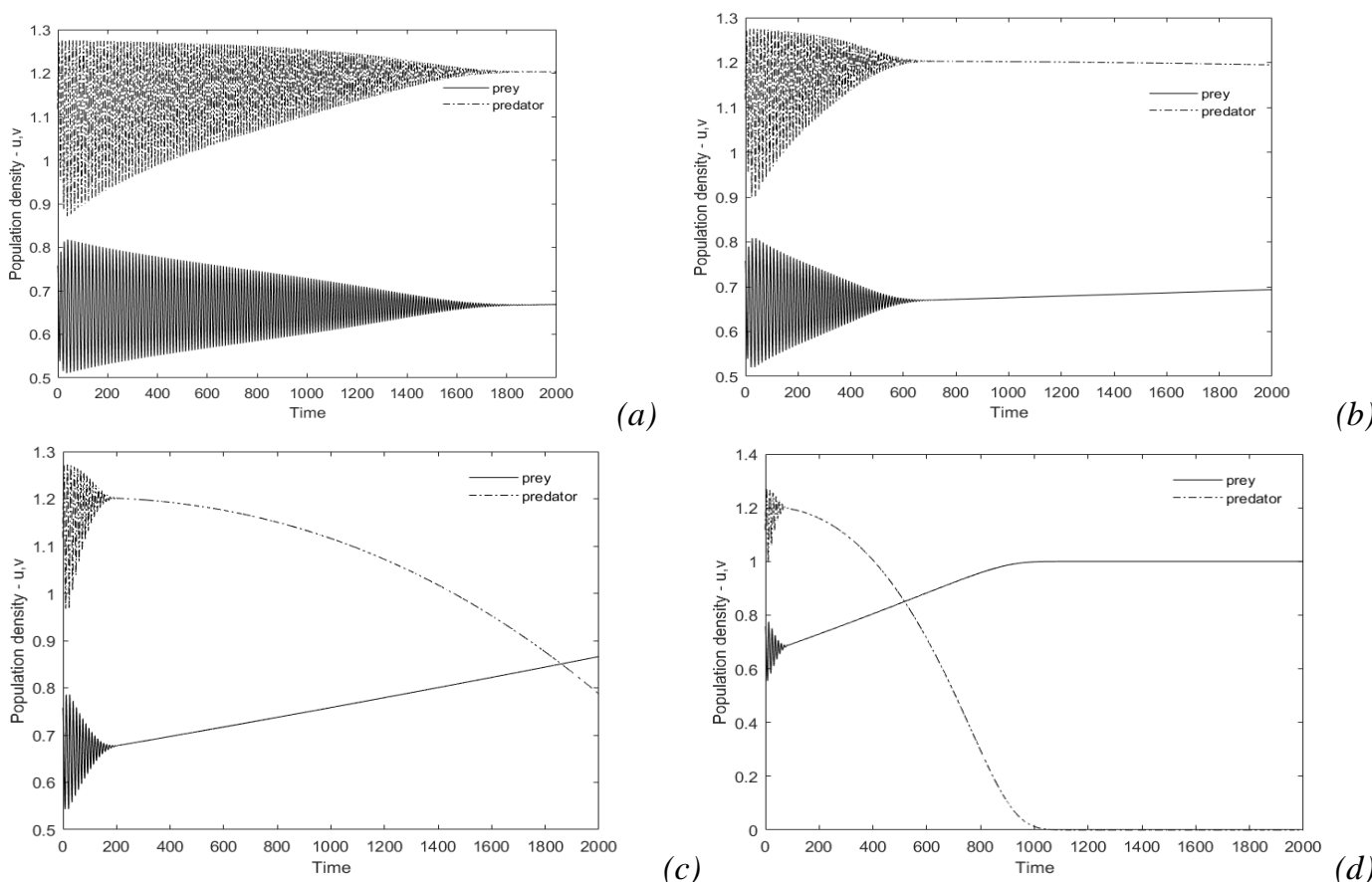

Figure 5. Snapshots of the prey (solid line) and predator (dashed-dotted line) versus time obtained for $\delta_{t}=0.495$ a) $\omega=3 \times 10^{-6}$, b) $\omega=1 \times 10^{-5}$, c) $\omega=55 \times 10^{-6}$ and d) $\omega=2 \times 10^{-4}$. The initial values of the system are obtained from Eqs.7-8 for given system parameters defined in Section II.
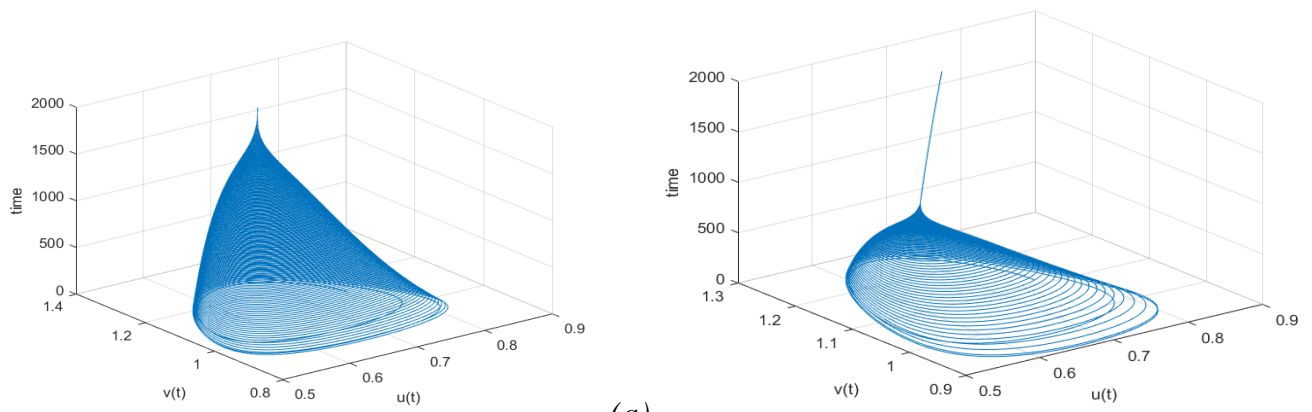

(a)

(b)
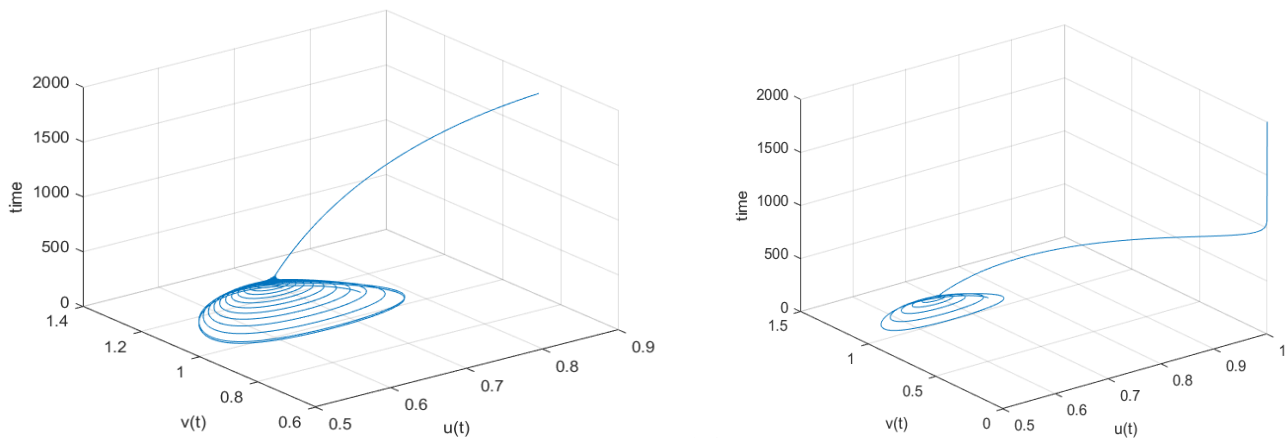

(c)

(d)

Figure 6. Phase plane structure for prey and predator for fixed values of delta in time $\delta_{t}=0.495$ a) $\omega=3 \times 10^{-6}$, b) $\omega=1 \times 10^{-5}$, c) $\omega=55 \times 10^{-6}$ and d) $\omega=2 \times 10^{-4}$ for $t=2000$. The initial values of the system are obtained from Eqs.7-8 for given system parameters defined in Section II. 


\section{CONCLUDING REMARKS}

In this work it is shown that using predator-prey system [24], the temporal dynamics can become stabilise under the effect of the temporal change in predator mortality rate. By means of numerical simulations, the structure of system temporal distribution is revealed for linearly decreasing or increasing values of $\delta$ in time. The temporal structure of the system gives important information when the predator mortality rate is closer to the extinction point. Here it is observed that the system has rich temporal dynamics depending on both Allee effect and the varying mortality rate of predator.

The obtained results show that species temporal variation and also the extinction of species can be interpreted with the slope in mortality rate of predator. If the mortality rate of predator is decreased, i.e., the case for $\delta=\delta_{t}-\omega\left(t-t_{1}\right)$, the population density of predator is increased. Hence the stress on prey population increase and the system pushes the prey to extinct. And that is which it is obtained in the numerical simulations. Accordingly, if the mortality rate of predator is increased, i.e., the case for $\delta=\delta_{t}+\omega\left(t-t_{1}\right)$, the population density of predator is decreased and it facilitates the growth of prey. This result is coincide the results obtained in the numerical simulations.

In conclusion, the most interesting question evokes here that whether increasing rate of predator mortality can prevent the prey extinction. This situation is examined in the case where $\delta$ is chosen as an increasing function in time and it is observed that the extinction of predator facilitates the growth of prey and it reaches its carrying capacity.

\section{ACKNOWLEDGEMENTS}

This research has been supported by Amasya University Scientific Research Projects Coordination Unit. Project Number: FBM-BAP 17-0258.

\section{REFERENCES}

[1] Allee, W. C. (1931). Animal Aggregations, a Study in General Sociology. University of Chicago Press, Chicago, IL

[2] Allee, W. C., \& Bowen, E. S. (1932). Studies in animal aggregations: mass protection against colloidal silver among goldfishes. Journal of Experimental Zoology, 61(2), 185-207.

[3] Stephens, P. A., Sutherland, W. J., \& Freckleton, R. P. (1999). What is the Allee effect? Oikos, 185-190.

[4] Tsoularis, A., \& Wallace, J. (2002). Analysis of logistic growth models. Mathematical Biosciences, 179(1), 21-55.

[5] Blumberg, A. A. (1968). Logistic growth rate functions. Journal of Theoretical Biology, 21(1), 42-44.

[6] Amarasekare, P. (1998). Allee effects in metapopulation dynamics. The American Naturalist, 152(2), 298302.

[7] Sekerci, Y. (2020). Climate change effects on fractional order prey-predator model. Chaos, Solitons \& Fractals, 134, 109690.

[8] Lewis, M. A., \& Kareiva, P. (1993). Allee dynamics and the spread of invading organisms. Theoretical Population Biology, 43(2), 141-158.

[9] Courchamp, F., Clutton-Brock, T., \& Grenfell, B. (1999). Inverse density dependence and the Allee effect. Trends in Ecology \& Evolution, 14(10), 405-410.

[10] Odum, E. P. (1953). Fundamentals of ecology. xii, 387 pp. W. B. Saunders Co., Philadelphia, Pennsylvania, and London, England. 
[11] Courchamp, F., Berec, L., \& Gascoigne, J. (2008). Allee effects in ecology and conservation. Oxford University Press.

[12] Allee, W.C., Emerson, O., Park, T., \& Schmidt, K. (1949). Principles of Animal Ecology. Saunders, Philadelphia.

[13] Allee, W.C. (1951). Cooperation Among Animals. Henry Shuman, New York.

[14] Allee, W.C. (1958). The Social Life of Animals. Beacon Press, Boston.

[15] Ye, Y., Liu, H., Wei, Y. M., Ma, M., \& Zhang, K. (2019). Dynamic study of a predator-prey model with weak Allee effect and delay. Advances in Mathematical Physics, 27(4), 943-953.

[16] Wang, J., Shi, J., \& Wei, J. (2011). Predator-prey system with strong Allee effect in prey. Journal of Mathematical Biology, 62(3), 291-331.

[17] Banerjee, M., Mukherjee, N., \& Volpert, V. (2018). Prey-predator model with a nonlocal bistable dynamics of prey. Mathematics, 6(3), 41 .

[18] Han, R., \& Dai, B. (2019). Spatiotemporal pattern formation and selection induced by nonlinear crossdiffusion in a toxic-phytoplankton-zooplankton model with Allee effect. Nonlinear Analysis: Real World Applications, 45, 822-853.

[19] Morozov, A., S. Petrovskii, \& Li, B.L. (2006). Spatiotemporal complexity of patchy invasion in a predator-prey system with the Allee effect, Journal of Theoretical Biology, 238(1), 18-35.

[20] Petrovskii, S., Morozov, A. \& Venturino, E. (2002) Allee effect makes possible patchyinvasion in a predator-prey system, Ecological. Letters, 5(3), 345-352.

[21] Sun, G. Q. (2016). Mathematical modeling of population dynamics with Allee effect. Nonlinear Dynamics, $85(1), 1-12$.

[22] Yao, S. W., Ma, Z. P., \& Cheng, Z. B. (2019). Pattern formation of a diffusive predator-prey model with strong Allee effect and nonconstant death rate. Physica A: Statistical Mechanics and its Applications, 527, 121350 .

[23] Petrovskii, S., Morozov, A., \& Li, B.L. (2005). Regimes of biological invasion in a predator-prey system with the Allee effect. Bulletin of Mathematical Biology. 67(3), 637-661.

[24] Murray, J.D. (1989). Mathematical Biology. Springer, Berlin.

[25] Nisbet, R.M., \& Gurney, W.S.C. (1982). Modelling Fluctuating Populations. Wiley, Chichester.

[26] Sherratt, J.A. (2001). Periodic travelling waves in cyclic predator-prey systems. Ecological Letters, 4, 3037. 